\title{
GESTÃO DE RESÍDUOS NA CONSTRUÇÃO CIVIL: UM ESTUDO EM BELO HORIZONTE E REGIÃO METROPOLITANA
}

\section{Waste management in construction: a study in Belo Horizonte and the metropolitan area}

\author{
Izabella Caroline de Almeida Leite ${ }^{1}$, João Luís Corrêa Damasceno², \\ Alexandre Magrineli dos Reis ${ }^{3}$, Marina Alvim ${ }^{4}$
}

Recebido em 02 de dezembro de 2016; aceito em 28 de agosto de 2017; disponível on-line em 07 de novembro de 2017.

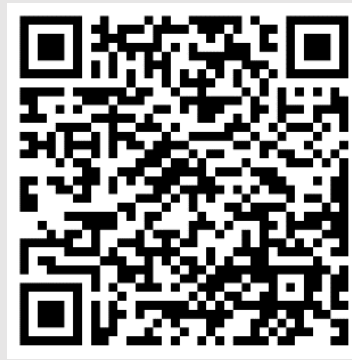

PALAVRAS CHAVE:

Gestão de resíduos Construção civil; Gerenciamento RCC Reciclagem Meio ambiente

KEYWORDS:

Waste management Civil construction; RCC Management Recycling Environment
RESUMO: O presente estudo teve como objetivo geral analisar a gestão de resíduos na construção civil no município de Belo Horizonte (MG) e região metropolitana. Para isso, foi elaborada uma pesquisa de campo. A revisão bibliográfica teve por objetivo identificar, na literatura, os processos de gerenciamento utilizados pelos municípios, bem como verificar o que preconiza a legislação vigente. $O$ universo da pesquisa elencou o município de Belo Horizonte e a região metropolitana, constituída por 34 municípios. A realização da pesquisa permitiu adquirir conhecimentos sobre o gerenciamento de Resíduos de Construção Civil (RCCs), tanto nos aspectos teóricos quanto nas informações obtidas na coleta de dados por meio do questionário de pesquisa. De modo geral, o setor de construção civil é um grande gerador de RCCs e ainda faltam políticas públicas, nas esferas federais, estaduais e municipais, para auxiliar gestores a criar estruturas capazes de proporcionar uma gestão eficaz, minimizando os impactos dos resíduos no meio ambiente. Foi possível perceber a carência quanto ao incentivo do processo de reciclagem nos municípios, que poderia ser um facilitador na gestão dos RCCs.

ABSTRACT: The present study had as general objective to analyze the waste management in civil construction in the city of Belo Horizonte (MG) and metropolitan region. For this, a field research was developed. The bibliographic review aimed to identify, in the literature, the management processes used by the municipalities, as well as verify what the current legislation recommends. The research universe listed the municipality of Belo Horizonte and the metropolitan region, made up of 34 municipalities. The research carried out allowed to acquire knowledge about the management of Civil Construction Waste (RCCS), both in the theoretical aspects and in the information obtained in the data collection through the research questionnaire. In general, the construction industry is a great generator of RCCs, and there is still a lack of public policies at federal, state and municipal levels to help managers create structures capable of effective management while minimizing the impacts of waste on the environment. It was possible to perceive the lack of incentive of the recycling process in the municipalities, which could be a facilitator in the management of RCCs.

\section{* Contato com os autores:}

1e-mail: iza.almeidaleite@hotmail.com (I. C. A. LEITE)

Graduando em Engenharia Civil, Centro Universitário Izabela Hendrix.

2e-mail: joaoluistec@yahoo.com.br (J. L. C. DAMASCENO)

Graduando em Engenharia Civil, Centro Universitário Izabela Hendrix.

${ }^{3}$ e-mail: alexandre.magrineli@gmail.com ( A. M. Reis)

Mestre, Professor orientador de conteúdo, Centro Universitário IzabelaHendrix.

4e-mail: marina.alvim@izabelahendrix.ed.u.br (M. ALVIM)

Doutora em Biologia ambiental, Professor doutor em metodologia, Centro Universitário Izabela Hendrix. 


\section{INTRODUÇÃO}

A construção civil contribui significativamente para $\mathrm{o}$ crescimento econômico do país, gerando emprego, renda e comercialização de insumos, equipamentos e serviços em seu processo produtivo. $O$ grande desafio do século XXI será, sem dúvida, conciliar desenvolvimento econômico e preservação ambiental, ou seja, compatibilizar atividade produtiva com conceito de desenvolvimento sustentável (KARPINSK et al., 2009).

Os países em desenvolvimento apresentam problemas ambientais acentuados, principalmente por não existirem políticas públicas que tratem os problemas ambientais de maneira prioritária e emergencial. Segundo Moura (2011), o capitalismo, com seu processo de expansão, têm ocasionado concentração de população e produção nas cidades e levado ao predomínio da sociedade urbana de hoje, com graves problemas de contaminação, congestionamento e desigualdades na satisfação das necessidades sociais básicas de grande parte da população. Nesse cenário, a construção civil busca crescer juntamente com o aumento da população, procurando atender suas expectativas. Porém, o excesso de resíduos gerados pelo crescimento demográfico descontrolado e o aumento da renda causam impacto na quantidade de resíduos gerados pelo setor. Esse é um dos problemas enfrentados pela Administração Pública, sendo que o alto custo gerado pela limpeza e remoção de resíduos depositados em locais inapropriados tem se agravado cada vez mais (OLIVEIRA e MENDES, 2008).

Estudos realizados no Brasil sobre as características das "cidades sustentáveis" apontaram a indústria da construção civil como um setor a ser aperfeiçoado, uma vez que causa grande impacto sobre o meio ambiente em razão do consumo de recursos naturais ou extração de materiais de jazidas (pedras ornamentais etc.); do consumo de energia elétrica nas fases de extração, transformação, fabricação, transporte e aplicação; da geração de resíduos decorrentes de perdas, desperdício e demolições, bem como do desmatamento e de alterações no relevo (BRASIL, 2002a). Quanto às externalidades geradas pelo setor, outro ponto relevante consiste na implantação de sistemas de gestão de Resíduos da Construção Civil (RCCs) eficientes, buscando evitar os custos de retrabalho e reduzir problemas relativos a descarte em locais inadequados. Para uma gestão de RCCs sustentável, a captação, coleta e a reciclagem destes pode ser um instrumento útil e eficaz (RODRIGUES, 2011).

Quanto à problemática deste estudo, eventos que ocorreram no Brasil fomentados pelo Governo, como a Copa do Mundo de 2014 e as obras do Programa de Aceleração do Crescimento (PAC), são exemplos do crescimento de obras de infraestrutura que provocaram o aumento na geração de RCCs. (MARTINS, 2012). Assim, é fundamental para o setor utilizar um sistema de gestão que possibilite reduzir os custos das obras e o volume de desperdícios e viabilize o uso das sobras de materiais. Essas ações podem minimizar impactos ambientais negativos, tais como consumo de recursos naturais desnecessários, degradação ambiental e problemas de saúde pública (BARRETO, 2005).

A indústria da construção civil tem papel fundamental no desenvolvimento econômico e social do país, porém ainda é vista como grande geradora de impactos ambientais, tanto pelo consumo de recursos naturais, modificação da paisagem ou geração de RCCs. No âmbito governamental, objetivando minimizar os impactos ao meio ambiente, houve, de forma específica, o estabelecimento de um regulamento antes mesmo de uma política pública geral para a gestão dos resíduos no país, a Resolução CONAMA n. 307, (BRASIL, 2002). O documento estabeleceu as diretrizes, os critérios e os procedimentos para a gestão dos Resíduos da Construção Civil (BRASIL, 2002a). Posteriormente, tal política foi aprovada e sancionada na forma da Lei no 12.305, 
de 2 de agosto de 2010, regulamentada pelo Decreto no 7.404, de 23 de dezembro de 2010, firmando, de forma expressa, que os geradores devam ser responsáveis pelos seus resíduos, abrangendo inclusive aqueles das atividades voltadas para a construção (BRASIL, 2010). A pergunta norteadora do presente estudo é: como ocorre a gestão de resíduos na construção civil em Belo Horizonte (MG) e região metropolitana?

Estima-se que um valor médio de 0,50 t por habitante de RCC é gerado anualmente em algumas cidades brasileiras. Contudo, ainda existe grande dificuldade de se estabelecerem estimativas de geração, tratamento e disposição exata em níveis estaduais, municipais e nacionais. As discussões entre a União, os Estados e os Municípios, o setor produtivo e a sociedade sobre a Política Nacional de Resíduos Sólidos - PNRS têm tido forte articulação no sentido de identificar soluções para os problemas graves e de grande abrangência territorial provocados pelo descarte incorreto, resultando na degradação ambiental. O gerenciamento adequado dos RCCs ainda encontra obstáculos pelo desconhecimento da natureza dos resíduos e pela ausência de cultura de separação, entre outros. Dessa forma, conhecer e diagnosticar os resíduos gerados possibilitará o melhor encaminhamento para o plano de gestão e o gerenciamento dos RCCs (BRASIL, 2012).

Desse modo, o RCC representa um grave problema para as cidades brasileiras. Sua gestão deve ser realizada no sentido de evitar que sejam abandonados e se acumulem em margens de rios, rodovias, terrenos baldios ou outros locais inadequados. Pensando nestes fatores em um contexto regional, faz-se necessário analisar a gestão de resíduos na construção civil em Belo Horizonte e região metropolitana, buscando identificar mecanismos apropriados para sua gestão.

A realização desta pesquisa se tornou relevante a partir do momento que buscou identificar de que forma tem sido conduzido o processo de gerenciamento de resíduos da construção civil e quais as consequências para a sociedade e o meio ambiente. Como justificativa acadêmica, este estudo possa contribuiu com discussões teóricas e práticas sobre o tema gerenciamento de resíduos na construção civil no meio científico. Como justificativa pessoal e profissional este estudo possibilitou agregar conhecimento e informações para os pesquisadores em sua formação.

\section{OBJETIVOS}

O presente estudo teve como objetivo analisar o atual estado da gestão de resíduos na construção civil no município de Belo Horizonte (MG) e região metropolitana.

\section{METODOLOGIA}

Para o desenvolvimento da presente pesquisa, foi elaborado um estudo de caráter exploratório envolvendo uma pesquisa de campo. A revisão bibliográfica teve por objetivo identificar na literatura os processos de gerenciamento utilizados pelos municípios, verificou-se ainda o que preconiza a legislação vigente. A pesquisa de campo e o levantamento de dados sobre o processo de gestão de resíduos procurou averiguar a rotina de coleta, transporte, tratamento e disposição dos resíduos nos últimos seis meses compreendendo o período de dezembro de 2015 à junho de 2016 . Este tipo de pesquisa possibilitou a investigação do problema, de modo a explicitá-lo, por meio de pesquisa bibliográfica e aplicação de questionários com gestores, secretários e diretores do setor do meio ambiente. Foram elaborados (Carta de anuência, Termo de Consentimento Livre e Questionário de pesquisa) todos enviados aos gestores no intuito de informá-los sobre o estudo e coletar autorização para elaboração da pesquisa no município.

Quanto ao universo e amostra da pesquisa, Belo Horizonte e os municípios no entorno foram formalizados como região metropolitana - RMBH - em 1973, sendo inicialmente composta por $14 \mathrm{e}$, atualmente, por 
34 municípios. Cabe ressaltar que Belo Horizonte tem desempenhado um papel importante neste conjunto de cidades, pelo fato de ser a capital e por sua expressão populacional e econômica. A criação da RMBH seguiu uma tendência nacional: foram criadas nove RMs em todo país pela Lei complementar no 14, de 8 de junho de 1973. Essa ação foi uma resposta à necessidade de desenvolvimento planejado dessas áreas, que já eram, naquele momento, apresentavam maiores desafios urbanos em função de sua população e se desenvolvimento econômico (MINAS GERAIS, 1973).

Portanto, o universo da pesquisa elencou o município de Belo Horizonte e a região metropolitana. A área de abrangência do presente estudo foram os seguintes municípios: Belo Horizonte, Betim Caeté, Contagem, Ibirité, Lagoa Santa, Nova Lima, Pedro Leopoldo, Raposos, Ribeirão das Neves, Rio Acima, Sabará, Santa Luzia e Vespasiano, da norma original de 1973, Brumadinho; Esmeraldas; Igarapé e Mateus Leme, incluídos em 1989; Juatuba, São José da Lapa, Florestal, Rio Manso, Confins, Mário Campos, São Joaquim de Bicas e Sarzedo, incorporados entre 1993 e 1997. Soma-se ainda em 2000 os municípios de Baldim, Capim Branco, Jaboticatubas, Taquaraçu de Minas, Itaguara, Matozinhos e Nova União e 2002 o Município de Itatiauçu.

Para o procedimento de coleta de dados, foram aplicados 34 questionários, elaborados com base nos pressupostos teóricos desenvolvidos nesse estudo. Os respondentes foram abordados via contato telefônico e, em seguida, foi enviado o questionário por e-mail. 0 local de realização da pesquisa foram as Prefeituras municipais da região metropolitana de Belo Horizonte, incluindo a capital. Os participantes foram os "coordenadores" da área de gestão de resíduos, o início da pesquisa ocorreu a partir da assinatura da Carta de Anuência, em seguida assinou-se o Termo de Consentimento e houve o preenchimento do questionário. Quanto aos riscos de participação foi informado aos entrevistados sobre o desconforto em compartilhar informações pessoais ou confidenciais e sua escolha de não responder. Conforme preconiza a legislação, esse estudo não realizou nenhuma intervenção ou modificação intencional nas variáveis fisiológicas, psicológicas e sociais dos indivíduos que participam do estudo. Quanto aos benefícios, verificou-se a contribuição do conhecimento neste debate "Gestão de resíduos", podendo somar para melhorias neste processo junto às prefeituras.

Adotou-se, também, a pesquisa bibliográfica, cujo principal objetivo foi adquirir informações acerca dos temas Resolução Conama n. 을 (BRASIL, 2002); Gestão de resíduos sólidos da construção civil; Geração de resíduos sólidos da construção civil; Classificação; PGRCC - Plano de Gerenciamento dos Resíduos de Construção Civil; Modelos de gerenciamento de resíduos e Reciclagem na Construção Civil. Para teorizar sobre o assunto, foram analisados artigos científicos de referências nacionais e internacionais, dissertações nacionais, disponibilizadas na internet, por meio dos endereços eletrônicos das principais universidades sobre gerenciamento de resíduos na construção civil. Para a tabulação e análise dos dados obtidos, foram seguidos os seguintes passos: As questões foram tabuladas no (access) e após categorizadas de acordo com os respondentes criando se as siglas (PM1 à PM10) as questões abertas foram agrupadas no sentido de captar ideias ou padrões de resposta de acordo com palavras-chave identificadas na pesquisa.

$$
\text { Após a coleta, tabulação e }
$$

categorização dos dados foi realizada a interpretação dos dados por meio da técnica análise de conteúdo, foi feita a organização em categorias, tendo como foco o material extraído dos depoimentos registrados. Bardin (1977) entende que a análise de conteúdo é um conjunto de técnicas de análise das comunicações, utilizada para estudar e analisar material qualitativo, buscando a melhor compreensão de uma comunicação ou discurso, além de relacionar suas características gramaticais às ideológicas e teóricas, podendo a partir daí, extrair aspectos relevantes para a pesquisa. 


\section{RESÍDUOS: DOS ASPECTOS GERAIS AOS RESÍDUOS DA CONSTRUÇÃO CIVIL}

A gestão de resíduos sólidos se enquadra nas atividades de saneamento básico, pois existe a interdependência entre este, a saúde e o meio ambiente. Portanto, as ações de gerenciamento de resíduos da construção civil devem ser interrelacionadas para contribuir com a melhoria da qualidade ambiental proporcionada a população (SILVA et al. 2015). Figueiredo (1994), alerta que todo processo econômico gera resíduos. Mesmo sendo considerados inservíveis por grande parcela da sociedade, os resíduos possuem, aproximadamente, $40 \%$ de materiais recicláveis. Os RCCs foram inicialmente definidos na legislação brasileira como o conjunto dos produtos não aproveitados das atividades humanas nas atividades de implantação e transformação dos bens de consumo na construção civil (BRASIL, 2002). Posteriormente, o art. 13, inciso I, h da Lei n. o 12.305/2010 (BRASIL, 2010), ao estabelecer uma classificação para os vários tipos de resíduos também definiu estes como "os gerados nas construções, reformas, reparos e demolições de obras de construção civil, incluindose os resultantes da preparação e escavação de terrenos para obras civis".

O diagnóstico de geração de resíduos oriundos da construção civil nas cidades brasileiras necessita de estimativas da área construída, de quantificação de volumes por empresas coletoras, do monitoramento de descargas nas áreas de disposição final dos resíduos de construção civil, permitindo, assim, uma quantificação confiável, que pode ser utilizada em todo município que possui cadastro de construções licenciadas (PINTO, 2005). Os RCCs normalmente são denominados de "entulhos" e, em termos técnicos, são todo o resíduo de material usado na realização de obras em atividades de construção civil, sendo oriundos das etapas de infraestrutura, demolições, reformas, restaurações, reparos e construções novas, ou seja, é todo o conjunto de fragmentos ou restos de pedregulhos, areias, materiais cerâmicos, argamassa, aço e madeira (JOHN, 2010).

A construção civil se destaca na economia nacional, sendo responsável por uma parcela significativa do Produto Interno Bruto (PIB) do país. Tem grande relevância pelo contingente de mãode-obra direta empregada. Entretanto, o setor vem sofrendo de forma genérica uma estabilização (SINDUSCON, 2008). De acordo com Souza (2004) as discussões sobre as questões ambientais têm ganhado conotação no cenário nacional, uma vez que desperdiçar materiais, seja na forma de resíduo (mais comumente denominado entulho de construção) ou sob outra natureza, significa desperdiçar recursos naturais, o que coloca a indústria da construção civil no centro das discussões na busca pelo desenvolvimento sustentável nas suas diversas dimensões (SOUZA, et al. 2004).

\subsection{GESTÃo DE RESÍDUOS SÓLIDOS DA CONSTRUÇÃO CIVIL}

$\mathrm{Na}$ atual conjuntura, os municípios brasileiros têm como foco principal o manejo adequado e sustentável dos resíduos gerados pelos domicílios e a área da saúde. Contudo, é fato que aqueles gerados pela construção civil têm uma participação importante no conjunto daqueles produzidos, podendo alcançar a cifra expressiva de até duas toneladas de entulho para cada tonelada de resíduo domiciliar. Portanto, torna-se necessário que as cidades do país e seus gestores desenvolvam e implementem políticas públicas direcionadas ao gerenciamento desses resíduos (BRASIL, 2010). Os resíduos gerados nas obras e seus canteiros devem ser segregados na fonte e descartados conforme a legislação. É obrigação de todos os colaboradores descartá-los adequadamente. Assim, cabe aos gestores disponibilizar orientações de fácil acesso nos locais e frentes de serviço por meio de placas de orientação, cartilhas e treinamentos (SICEPOT, 2014). A Resolução CONAMA n. o 275, de 25 de abril 2001 (BRASIL, 2001), estabeleceu o código de 
cores para os diferentes tipos de resíduos, a ser adotado na identificação de coletores e transportadores, bem como nas campanhas informativas para a coleta seletiva.

0 gerenciamento dos resíduos oriundos da construção civil não deve ter ação corretiva e sim uma ação educativa, criando condições para que as empresas envolvidas possam exercer suas responsabilidades sem produzir impactos socialmente negativos. Karpinsk et al., (2009), aponta que o programa de ações educativas deve ser divulgado entre os pequenos geradores e coletores e apontado as opções para a correta disposição de resíduos no município, informando a rede de pontos de entrega voluntária e a possibilidade de solicitação telefônica da prestação de serviços, por meio de um sistema como o "disque coleta". Blumenschein (2007) por sua vez relata em seus estudos que um Sistema Integrado de Gerenciamento de RCCs envolve questões complexas, particularmente, no processo de produção da cadeia principal da cadeia produtiva da indústria da construção, ou seja, no processo construtivo.

\subsection{RECICLAGEM NA CONSTRUÇÃO CIVIL}

No cenário atual, 0 processo de reciclagem na construção civil no país tem se fortalecido no sentido de buscar soluções para o gerenciamento dos resíduos gerados por esta atividade. Essa vertente ganha força principalmente pela procura de novos materiais, que possam substituir as matérias-primas retiradas do meio ambiente. Porém, nosso processo de desenvolvimento da reciclagem ainda está muito atrasado em relação à Europa, que iniciou a ação após a Segunda Guerra Mundial e onde países como Holanda já conseguem atingir cerca de $90 \%$ de seu processo de reciclagem em RCCS (DORSTHORST e HENDRIKS, 2000). Estudos de Schneider e Philippi (2004) sobre a geração dos resíduos da construção civil mostram que essa questão é mundialmente reconhecida. O autor ressalta que os Estados Unidos da América, por exemplo, geram, aproximadamente, 136 milhões de toneladas de resíduos de construção e demolição (RCD) por ano.

O processo de reciclagem dos resíduos de construção é constituído das etapas de triagem, homogeneização, trituração, extração de materiais metálicos, eliminação de contaminantes e estocagem para expedição. 0 mercado brasileiro apresenta sinais de interesse no sentido de explorar o negócio de reciclagem na construção civil e não apenas o negócio de transporte, com experiências limitadas em ações das municipalidades (PINTO, 2005).

O município de Belo Horizonte, opera plantas de reciclagem, produzindo principalmente base para pavimentação. Estudos de Resende (2016) apontam os caminhos percorridos pelos RCC em Belo Horizonte, desde os diversos geradores, passando pelos intermediários (responsáveis pela triagem e reciclagem do material) até os receptores dos resíduos estão descritos na Figura 1. 


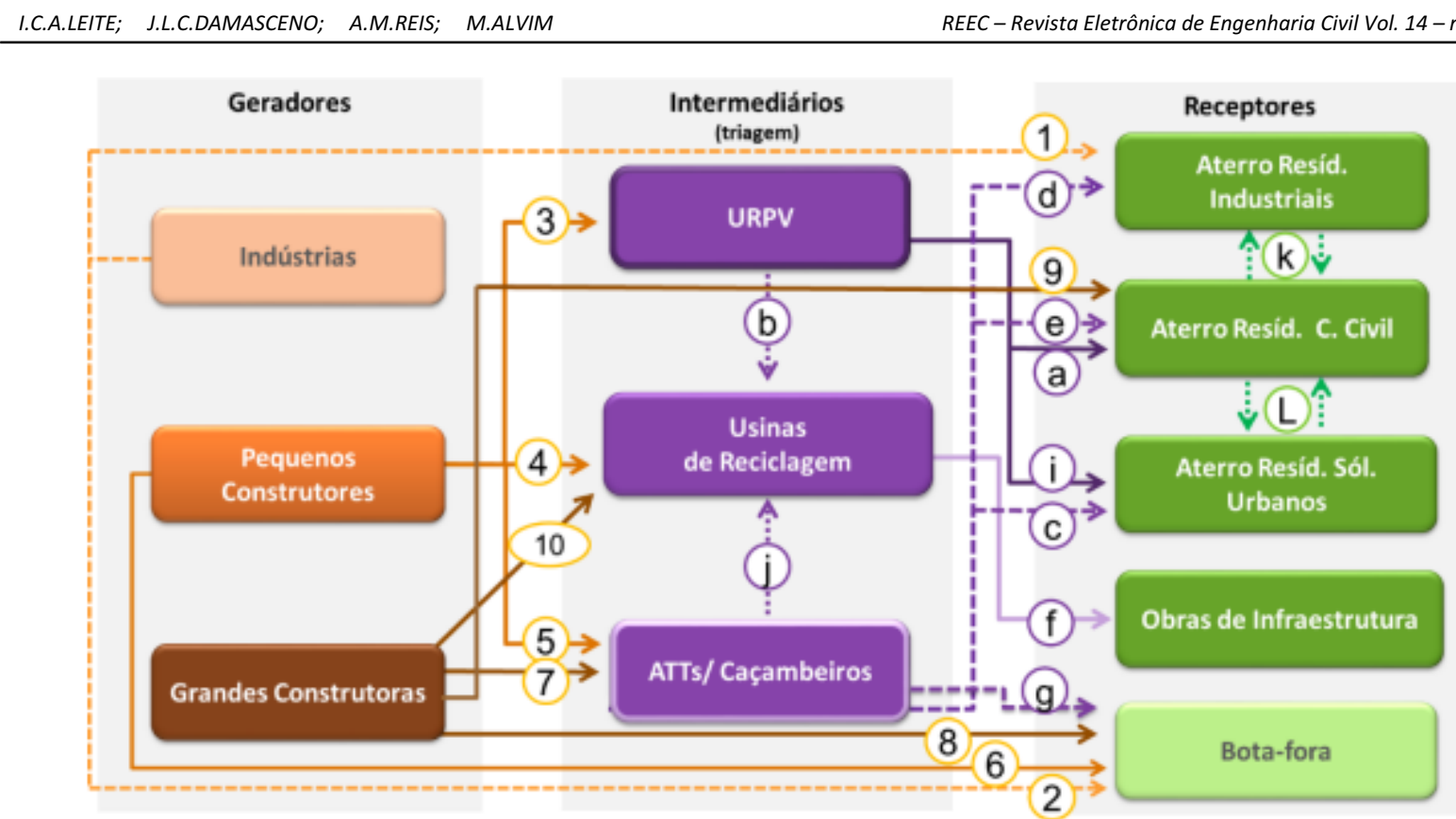

FIGURA 1: Fluxograma do gerenciamento de RCC em Belo Horizonte. FONTE: Resende (2016).

Segundo Resende (2016) a geração de resíduos ocorre em função das diversas obras de modificação (expansão ou reforma) que as empresas realizam em suas plantas de operação, de modo que a quantidade gerada é considerável, de acordo com informações disponibilizadas pelos receptores (aterro de resíduos industriais e botas foras) A redução de disposição dos RCC em locais inapropriados, ocorreu a partir de 1993 quando a prefeitura municipal (PBH) criou o Programa de Correção das Disposições Clandestinas e Reciclagem de Entulho, e a partir de então a cidade passou a ser considerada um caso de sucesso na gestão desses resíduos. No entanto, a dificuldade de se monitorar e mensurar o ciclo dos RCC (da geração à disposição final) ainda faz com que qualquer tomada de decisão, principalmente do poder público, seja dificultada. Desse modo, os estudos relacionados ao tema são considerados de grande relevância e novas pesquisas se mostram necessárias (RESENDE, 2016) Carneiro et al., (2001), citado por Silva (2007), afirma que, de modo geral, os processos de reciclagem têm equipamentos similares aos utilizados na produção de agregados naturais. Contudo, os sistemas de reciclagem de entulho podem ser classificados em função dos critérios e do rigor usados na eliminação dos contaminantes.

Fagury e Grande (2007) acreditam que os resíduos dos canteiros de obras podem ser empregados novamente como material de construção se devidamente reciclados. Os concretos, argamassas e rochas têm grande potencial para ser reciclados. No caso dos blocos, tijolos e cerâmicas, é possível reutilizá-los sem serem necessários processos de tratamento. Os solos, a areia e a argila podem ser reutilizados em obras viárias. Quanto aos metais ferrosos, podem ser reciclados e reaproveitados pelo setor de metalurgia. Os resíduos do gesso, se armazenados adequadamente em local seco, como em caixas com piso concretado ou caçambas, readquirem características químicas da gipsita, minério extraído o gesso e que pode ser reutilizado, sendo aproveitada na agricultura, devido ao seu efeito fertilizante (fonte de enxofre e de cálcio), ação corretiva de solos sódicos, funcionando como um condicionador de subsuperfície e de estercos (DRYWALL, 2011).

As indústrias recicladoras de RCCs podem ser consideradas como: emergente, quando o mercado de reciclados ainda não está consolidado, principalmente nas qualificações dos produtos, e 
madura, quando os agregados reciclados se tornam mercadoria concorrente e certificada, dispostos à venda nas lojas de material de construção (LIMA, 2013). Assim, executar a separação do RCC na fonte geradora dos resíduos beneficia a reciclagem e é imprescindível na obtenção de reciclados com melhor qualidade. Segundo Alves e Quelhas (2004), a indústria da construção civil é um grande reciclador de resíduos de outras indústrias e de sua própria atividade. Na ponta geradora do resíduo, a reciclagem significa redução de custos e até mesmo novas oportunidades de negócios.

Cunha Júnior (2005) reconhece que a necessidade de se aproveitar os resíduos da construção civil não ocorre somente pela vontade de economizar, mas é também uma atitude fundamental para a preservação ambiental. 0 sucesso de um processo de reciclagem depende muito de fatores regionais, que devem ser avaliados para mensurar se uma determinada cidade ou região possui condições de implantação favoráveis ou desfavoráveis (LANGUELL, 2001).

\subsection{IMPACTOS AMBIENTAIS CAUSADOS PELO DESCARTE INADEQUADO DO RCC}

Já foi mencionado anteriormente o papel da construção civil na economia do país e em seus impactos ambientais. Isto se produz a partir do consumo de recursos naturais e da geração de resíduos, mas também podem surgir a partir da alteração da paisagem (CASTRO, 2012). Tozzi (2006) cita Degani (2003) quando reconhece que uma das maiores preocupações referentes à geração descontrolada de RCCs é a disposição irregular. Degani (2003) afirma em seus estudos que a disposição irregular engloba todos despejos clandestinos em vias e logradouros públicos, terrenos baldios e fundos de vales. Tais despejos são responsáveis pelo surgimento de bota-foras irregulares, que acabam se transformando em lixões, o que tem sido uma grande preocupação esse tipo de descarte irregular.

Para o Sinduscon - SP (2005), a disposição irregular está relacionada à carência de políticas públicas que disciplinem e ordenem os fluxos da destinação dos resíduos da construção civil, associada ao descompromisso dos geradores no manejo e, principalmente, na destinação dos resíduos, provocando os seguintes impactos ambientais: degradação das áreas de manancial e de proteção permanente; proliferação de agentes transmissores de doenças; assoreamento de rios e córregos; obstrução dos sistemas de drenagem (piscinões, galerias e sarjetas); ocupação de vias e logradouros públicos por resíduos, com prejuízo para a circulação de pessoas e veículos, além da própria degradação da paisagem urbana e existência e acúmulo de resíduos que podem gerar risco devido a sua periculosidade.

\subsection{PLANO DE GERENCIAMENTO DOS RESÍDUOS DE CONSTRUÇÃO CIVIL (PGRCC)}

De acordo com a Resolução CONAMA no 307/2002 (BRASIL, 2002), os planos de Gerenciamento de Resíduos de obra, constantes do item Projetos de Gerenciamento de Resíduos, são basilares para a indução de procedimentos disciplinados na cadeia de produção da construção civil. Esta norma é exigência da Política Nacional de Resíduos Sólidos - PNRS - a todas as empresas da área de construção. Seu principal objetivo é designar os responsáveis pelo manejo correto dos resíduos gerados pela obra (BRASIL, 2010). Portanto, para executar o planejamento de um projeto dessa natureza, é necessário considerar as seguintes indagações: há política da qualidade em sua empresa? E como posso estruturar o PGRCC em sintonia com tal política? Desse modo, ao iniciar a implantação do plano é prudente criar uma experiência piloto para única obra, validando assim, metodologia que será utilizada pela instituição. É fundamental que todos os procedimentos operacionais do PGRCC sejam considerados na sua elaboração e os princípios e métodos seja a tradução do projeto. Ressalta-se que o gerenciamento dos resíduos é um tema muito importante e deve ser pautado na classificação dos resíduos gerados obrigatoriamente conforme CONAMA $n^{\circ} 307$ 
(BRASIL, 2002) Classes A, B, C e D definidas em sua resolução (ROS; MAZONI, 2006).

\section{RESULTADOS E DISCUSSÕES}

Nesta seção, apresentam-se os resultados pertinentes a coleta de dados desta pesquisa, no sentido de identificar como ocorre o processo de gestão de resíduos em Belo Horizonte e região metropolitana. O bloco de questões a seguir representa as informações específicas da pesquisa sobre a gestão de resíduos no município os resultados tabulados para as 10 prefeituras analisadas estão descritos na Tabela 1.

\section{TABELA 1: Gestão de RCC nas prefeituras.}

\section{Bloco de questões sobre Gestão de RCC nas prefeituras \\ NÃO \\ SIM

㟧 $\quad \%$

Indique se o município possui legislação específica para a gestão de resíduos sólidos.

0

$0 \%$

10

$100 \%$

Indique se o município possui Plano de Gerenciamento de Resíduos Sólidos.

$1 \quad 10 \% \quad 9 \quad 90 \%$

Indique se o município possui Programa Integrado de Gerenciamento de Resíduos da Construção Civil (conforme legislação vigente).

$0 \%$

10

$100 \%$

Indique se a prefeitura desenvolveu programas ou realizou ações educativas voltados ao reaproveitamento e destinação final dos resíduos de construção civil (RCC).

Indique se a prefeitura tem cadastro de grandes geradores.

0

$0 \%$

10

$100 \%$

Indique se há sistema de coleta de RCC implantado no município.

6

$60 \%$

4

$40 \%$ 


\subsection{QUESTÕES ABERTAS}

Esse bloco de questões procurou identificar a opinião dos pesquisados sobre a 0 processo de Gestão de Resíduos no município. A opinião dos entrevistados quanto a existência de entrepostos oferecidos para os geradores de pequenos volumes de RCC.

Diversos [PM1]; A coleta dos RCC é realizada in loco, na área onde foi gerado. Há um local de transbordo temporário para depósito dos resíduos em casos de morosidade do transporte [PM2]; Não existe [PM3]; Um ponto que é terceirizado [PM4]; Um [PM5]; Não há no município entrepostos oferecidos para os geradores de pequenos volumes de RCC [PM6].

Diante dos relatos observa-se são poucos os entrepostos existentes nos municípios, dificultando o descarte para que os geradores de pequenos volumes de RCC. É necessário que medidas sejam tomadas no sentido de acabar com o descarte inadequado e melhorar as condições de trabalhos dos pequenos geradores de resíduos, talvez uma solução fosse 0 processo de terceirização, como o que existe em um dos municípios participantes da pesquisa.

Ao serem indagados sobre o perfil do profissional que atua nos entrepostos os respondentes apresentaram os depoimentos a seguir:

Como o local é apenas para transbordo e é temporário, atuam no local somente os motoristas dos caminhões $e$ máquinas para organização da área [PM2]; Não existe [PM3]; Aproximadamente 5, Ensino Fundamental e Médio [PM4]; 1 Ensino Médio [PM5]; Não há entrepostos [PM6]; 03 funcionários, Ensino Fundamental [PM7]; Não há [PM8]; Não se aplica [PM9]; Não existem entrepostos no município [PM10].

Para os entrevistados a maioria dos funcionários está em uma faixa de escolaridade de ensino médio e ou fundamental, e existe ainda a presença de motoristas e maquinários para execução dos serviços em uma das prefeituras. Outros afirmam não haver entrepostos no município.
As informações sobre os pontos de entrega de grandes volumes de resíduos são oferecidos pelo município, a existência de áreas de bota-fora e o tempo de vida útil de um destes locais.

Os resíduos são transportados pela própria prefeitura e encaminhados a um aterro de RCC devidamente licenciado, onde são realizadas triagem e destinação final dos demais resíduos. Não temos informação da vida útil do aterro [PM2]; Uma unidade que não é área de bota fora, vida útil aproximada de dez anos [PM3]; Um ponto, com vida útil aproximada de 2 anos [PM4]; Um bota fora, sem previsão de vida útil [PM5]; O município realiza a disposição final dos RCCs em parte da área denominada aterro do Mingu, e não cobra nenhuma taxa de coleta, transporte ou destinação final deste tipo de resíduos das empresas privadas usuárias do aterro do Mingu. Ainda, quando solicitado, a Secretaria de Obras e Serviços Urbanos (SEMOS) efetua a coleta de resíduos desse tipo sem custos, quando em pequenas quantidades. Segundo informações da SEMOS a vida útil do aterro é de 20 anos. No Plano Municipal de Saneamento Básico entregue em 06 de 2016 foram destacados 26 pontos de descarte [PM6]; Não há PM7; Sim 10 anos em média [PM8]; Primeira área de bota fora, também são usados no controle de erosão em lotes [PM9]; Não existe ponto de entregas de RCC [PM10].

Os gestores afirmam que nos municípios existem pontos de entrega de RCC e que a vida média dos aterros ou bota fora possui entre 2 e 10 anos. Contudo houve um município que afirmou que a vida de um aterro em seu município é de 20 anos. Em um município pequenos geradores de resíduos contam com 26 pontos de descarte, verificou-se também que algumas áreas de bota fora são usados em controle de erosão de lotes.

A avaliação da Prefeitura com relação a atuação das empresas construtoras e transportadoras de resíduos no que se refere a adaptação a nova lei são:

Só existe uma transportadora de resíduos que atende aos requisitos mínimos [PM3]; 
Estão se adaptando assim, como o município [PM4]; Em função do porte e da tipologia das atividades desenvolvidas, nos termos da Lei n 12.305, de 02 de agosto de 2010 que instituiu a política nacional de resíduos sólidos, há uma série de empreendedores operando no município que já dispõe ou devem elaborar seu plano de gerenciamento de resíduos sólidos, entretanto, não existe uma fiscalização efetiva para avaliar o cumprimento do plano [PM6]; O Plano de Gestão integrada de Resíduos Sólidos está em revisão [PM7]; Não querem se adaptar à lei. A grande maioria descarta os resíduos ao longo das vias pouco movimentadas [PM8]; Não se aplica [PM9]; É de extrema importância o planejamento e o Gerenciamento correto dos RCCs não apenas das empresas construtoras, mas também de toda a sociedade. Isso implica na redução, reaproveitamento ou destinação correta $e$ mais adequada [PM10].

Para os gestores, algumas prefeituras estão procurando se adequar as normas e regulamentos, contudo ainda são identificadas empresas que fazem o descarte de modo inadequado, utilizando vias e estradas para realizálos. Esta disposição irregular também é feita pela sociedade, que precisa ser conscientizada e educada, uma vez que o problema vem se agravando a cada dia. A possibilidade de criação de programas de reciclagem para minimizar os impactos ambientais causados por esta ação ilegal é uma das alternativas que os municípios podem adotar para minimizar os impactos ambientais, sociais e econômicos.

A opinião dos entrevistados sobre a maneira como a prefeitura encara a aceitação por parte das construtoras e transportadores no que se refere à Legislação expressa-se no Quadro 5.

No que tange a construtoras, as envolvidas com o município geralmente possuem um plano de gerenciamento de resíduos gerados e aprovados junto aos órgãos ambientais pertinentes. Já alguns transportadores independentes descartam os restos de entulhos, em beira de estradas $e$ áreas de pouco tráfego de veículos e pessoas,
- que gera bastante incomodo para o município em geral [PM2]; A transportadora se compromete a cumprir a legislação vigente [PM3]; Considera que a maioria das construtoras apresentam planos e propostas que não são executados servindo apenas para a aprovação do licenciamento [PM6]; Cumprem o Plano de Gerenciamento de Resíduos proposto pelo município [PM7]; Fiscaliza e autua as empresas [PM8]; Não se aplica [PM9]; É de extrema importância o aproveitamento dos RCCs em todas as construções, sejam ela por parte de construtoras ou pessoas comuns, em obras particulares ou públicas [PM10].

De um modo geral as prefeituras desenvolveram um bom relacionamento com as construtoras, sendo que, na opinião dos gestores, a maioria cumpre as determinações da legislação, apesar de ainda haver aqueles que realizam o descarte de maneira incorreta, mas ainda assim é necessário estabelecer um trabalho intensivo de conscientização e reaproveitamento quer seja pelas empresas, sociedade ou para qualquer um que lide com os resíduos gerados pela construção civil. É preciso haver uma maior efetividade quanto aos planos de gestão, não se pode permitir que eles sirvam apenas de aprovação para obtenção de licenciamento.

Quanto a cobrança de projetos de gerenciamento de RCC para aprovação da obra na Prefeitura, os relatos por parte dos entrevistados informam que:

Não (PMCON/PMITA/PMM/PMSJB); Sem previsão (PMMC); Sim, a partir de 2012 foram definidas diretrizes mais específicas para os projetos de gerenciamento de RCC. Entretanto, anterior a isto já era feita a cobrança por meio da Prefeitura Municipal $(P M N L) ; \operatorname{Sim}(P M S L, P M P L) ;$ Não há previsão (PMRA).

É importante ressaltar que medidas no sentido de estabelecer diretrizes e proporcionar melhorias no processo de gestão de resíduos são fundamentais, cobrar das empresas os projetos de RCCs é fundamental uma vez que envolve o município e seu entorno, e os benefícios gerados por um bom gerenciamento de resíduos 
beneficiam a sociedade, as empresas e todo o meio ambiente envolvido no município.

A indagação que buscou identificar se existe práticas estudadas e ou viabilizadas para que existam áreas de reciclagem de resíduos no município os resultados são:

Sim, previsto para implantação no município a partir de 2017 projeto referente a gestão do vice prefeito e candidato nestas eleições [PM2]; Ainda não existe [PM3]; Sim [PM4/PM7]; No momento nada efetivo. Apenas alguns estudos e propostas de empresas privadas [PM6]; Sim. Existe uma área que está em processo de licenciamento onde prevê o reaproveitamento e reciclagem dos materiais [PM8]; Não [PM9/PM10].

Diante dos resultados apresentados nesta questão percebeu-se a implantação de projetos e áreas de reciclagem nas prefeituras ainda é uma questão prematura, sendo necessário haver maior engajamento por parte dos gestores municipais para que a reciclagem se torne realidade para um número maior de municípios. Evidenciam-se também estudos e propostas por parte da iniciativa privada. Percebe-se que os processo de reciclagem são capazes de promover geração de renda e inclusão social, uma vez que muitas vezes possibilita tirar indivíduos que estão à margem da sociedade.

As dificuldades do município em relação a Gestão de RCCs expõe-se a seguir:

Em nosso município e região, há diversos locais vagos onde ainda populares depositam entulhos de forma inadequada contendo resíduos diversos misturados. A falta de uma legislação ambiental municipal incluindo-se ainda recursos para fiscalização e poder de autuações pelo município levam as pessoas e esse tipo de atitude, visto que as áreas mais próximas para destinação final ambientalmente adequada para os RCC requerem investimentos [PM2]; Falta maior dedicação, estudo e disponibilidade de tempo para gerenciar RCC [PM3]; Aprovação de Leis ambientais municipais pela Câmara dos Vereadores [PM4]; Dificuldades para elaboração do projeto $e$ dificuldades financeiras [PM5]; Falta de ações de regulação e de maior atuação da fiscalização municipal. Distância do aterro e topografia do munícipio contribuem para as práticas irregulares de bota fora. Falta estímulo à reciclagem de inertes e ações educativas voltadas para a prática da logística reversa [PM6]; Localização de área onde seja possível realizar o tipo de serviço, já que o município é cercado por unidades de conservação $e$ licenciamento dessa área para aterro e/ou Usina de Reciclagem de RCC. Precisamos de legislação específica de cobrança $e$ recolhimento [PM7]; resiliência dos construtores locais [PM8]; Falta de recursos para a construção de um aterro apropriado para esses resíduos [PM9]; Em primeiro lugar, a conscientização dos moradores locais a respeito da disposição irregular desse tipo de resíduo em terrenos baldios e ou lugares impróprios. A ausência de uma prévia segregação na fonte geradora é uma questão muito observada, pois é comum encontrar outros tipos de resíduos como, por exemplo, domésticos misturados a estes [PM10].

A falta de uma legislação específica para a gestão de resíduos no município é um elemento dificultador, além da questão financeira, para se construir aterros e usinas de reciclagem. Aliado a tudo isso ainda é preciso lidar com o descarte incorreto, proporcionado pela vulnerabilidade dos locais vago onde é feito o descarte irregular. Deveria existir uma fonte segregadora que possibilitasse melhor seleção e utilização dos resíduos, usinas de reciclagem seriam o ideal para o processamento e gestão de resíduos. A criação de programas educacionais, também é primordial para a população, os programas de conscientização e educação ambiental podem ensinar o modo correto de descarte de resíduos com o devido respeito ao meio ambiente e seu entorno.

\subsection{DISCUSSÃO DOS RESULTADOS}

Em relação ao primeiro objetivo que foi analisar a gestão de resíduos na construção civil no município de Belo Horizonte (MG) e região metropolitana, de modo geral percebeu-se que as instituições pesquisadas têm uma preocupação quanto ao gerenciamento de resíduos em seus municípios. Contudo as limitações de recursos e a falta de políticas públicas específicas voltadas para 
a gestão de RCCs apresentam-se como um dificultador no sentido de se obter resultados eficazes que possam minimizar os impactos ambientais provocados muitas vezes pela disposição irregular. Para Rodrigues (2011) é necessário que ocorra a implantação de sistemas de gestão de resíduos da construção civil (RCCs) eficientes buscando assim evitar os custos de retrabalho e a redução de problemas relativos à disposição irregular. Para uma gestão de RCC sustentável a captação, coleta e reciclagem destes pode ser um instrumento útil e eficaz.

O segundo objetivo tratou de analisar a situação atual dos resíduos da construção civil no município de Belo Horizonte e região metropolitana por meio de dados primários. Identificou-se que a gestão de resíduos ainda é precária, com seus gestores enfrentando dificuldades em relação a infraestrutura, recursos financeiros e a necessidade de elaboração de projetos que tenham como foco a gestão de RCCs nos municípios. É preciso criar diretrizes eficazes para o processo de gestão de resíduos nos municípios, principalmente no que tange à região metropolitana. O estudo demonstrou que muitas prefeituras possuem pouca geração de resíduos. Um dos municípios informou, por meio de contato telefônico, que a coleta de resíduos é responsabilidade das empresas vencedoras dos processos de licitação, essa é uma das condições impostas no contrato, o licitante vencedor deve ser responsável pelo processo de gestão de resíduos, a coleta, o descarte e todo o planejamento para gerenciar os resíduos gerados nas obras é gerenciado pelo licitante vencedor do contrato. A responsabilidade que há alguns anos era da prefeitura hoje foi transferida para as empresas privadas. Essa é uma ação importante e que pode ser disseminada para outros municípios mineiros. Desse modo poderia se minimizar os impactos ambientais provocados pelo descarte inadequado praticado contra o meio ambiente. Neste sentido, Gomes (1988) ressalta que nos países em desenvolvimento, os problemas ambientais se acentuam por não haver políticas públicas que tratem os problemas ambientais de maneira prioritária e emergencial.

Estudos de Silva et al., (2015) tiveram por finalidade analisar a investigar as práticas de gestão de resíduos da construção civil implementadas pelo poder público municipal em Belo Horizonte, há 10 anos já existia uma estreita relação com dos problemas ambientais com vários fatores macroeconômicos e sociais, aspectos como o crescimento populacional e urbano, a desigualdade na distribuição de renda e os processos de industrialização aumentou significativamente a geração de resíduo causando impactos no meio ambiente. Embora esse cenário venha se desenvolvendo ao longo dos anos, somente nas últimas duas décadas que as indagações políticas e científicas se intensificaram, ao mesmo tempo em que a problemática socioambiental ganhou maior destaque, tanto na mídia quanto no meio acadêmico. $E$, mesmo diante do crescente conhecimento sobre gestão ambiental e da maior pressão exercida pela sociedade e pelo Estado (através da legislação), diversos atores das cadeias produtivas, como os da indústria da construção civil, continuam depositando indiscriminadamente os resíduos de suas atividades. Em Belo Horizonte, cerca de 42\% dos resíduos coletados é entulho oriundo da construção civil, uma indústria de elevado potencial poluidor.

A Prefeitura de Belo Horizonte por meio da Superintendência de Limpeza Urbana criada pela Lei no 2.220 de 27 de agosto 1973 definida como autarquia municipal tem por finalidade prestar serviços de varredura, coleta, depósito, tratamento e transformação de lixo em todo o município de Belo Horizonte, além de possuir o Departamento de Programas Especiais responsável pelo Programa de Correção das Deposições Clandestinas e Reciclagem de Entulho e outros projetos específicos da área. Ressalta-se que desde a década de 1990, vem formulando no município políticas públicas e implementando um conjunto de práticas de gestão ambiental. No ano de 1993 iniciou-se o Programa de Correção 
Ambiental uma empresa de consultoria foi contratada pela superintendência para avaliar as condições de deposição do entulho da construção civil na cidade (SILVA et al., 2015).

Os resultados obtidos a partir dessa consultoria levaram a Prefeitura de Belo Horizonte a formular e programar uma política municipal de gestão integrada dos resíduos da construção civil envolvendo desde a regulamentação da política municipal de resíduos da construção civil; um plano integrado de gerenciamento desses resíduos; e projetos específicos para esse gerenciamento. Após incansáveis estudos e detalhamento das diretrizes a Prefeitura de Belo Horizonte organizou e programou na década de 1995, duas práticas de combate e prevenção: 1) a primeira, denominada "rede receptora do resíduo", envolvendo a implantação das URPVs, das estações de reciclagem de entulho e os aterros municipais de resíduos inertes; e 2 ) criou-se a rede programática, envolvendo práticas de gestão específicas: educação e informação, recuperação de áreas degradadas e projeto de fiscalização (SILVA, et al., 2015). O processo de gestão de resíduos corretos possibilita o desenvolvimento sócio econômico e a inclusão social, onde os diversos atores envolvidos se beneficiam os catadores e carroceiros, buscam os recursos nas empresas que deixam de fazer o descarte incorreto e fornecem a matéria prima para reciclagem, o que para o município também é fundamental, pois reduz os impactos ambientais e os custos de gerenciamento.

Oliveira e Mendes (2008) corroboram esta situação quando relatam que o excesso de resíduos gerados pelo crescimento demográfico descontrolado e o aumento da renda causam impacto na quantidade de resíduos gerados pelo setor. Este é um dos problemas enfrentados pela Administração Pública com o alto custo gerado pela limpeza e remoção de resíduos depositados em locais inapropriados, o que tem se agravado cada vez mais.

Outro autor que acredita no processo de reciclagem é Fagury e Grande (2007), que defende que os resíduos dos canteiros de obras, podem ser empregados novamente como material de construção se devidamente reciclados. Os concretos, argamassas e rochas têm grande potencial para ser reciclados, sendo que, no caso dos blocos, tijolos e cerâmicas é possível reutilizálos sem ser necessários processos de tratamento. Já os solos, a areia e argila podem ser reutilizados em obras viárias.

Para o objetivo que buscou identificar os modelos de gerenciamento de resíduos de construção civil utilizados pelo setor no município de Belo Horizonte e região metropolitana, não foi identificado um modelo específico para tal. Por isso recomenda-se uma nova etapa de estudos no sentido de aprofundar essa pesquisa de modo a se obter resultados específicos para essa indagação.

\section{CONSIDERAÇÕES FINAIS}

A realização desta pesquisa possibilitou uma melhora significativa nos conhecimentos dos pesquisadores quanto ao gerenciamento de RCC, tanto nos aspectos teóricos, quanto nas informações obtidas com a coleta de dados por meio do questionário de pesquisa. De modo geral o setor de construção civil é um grande gerador de Resíduos de Construção Civil (RCC) e apesar de haver resoluções estabelecidas pelo CONAMA, ainda faz se necessário uma maior intervenção governamental no sentido de auxiliar os gestores a criar estrutura capaz de proporcionar uma gestão eficaz, minimizando os impactos no meio ambiente. Foi possível perceber a carência quanto a incentivos ao processo de reciclagem nos municípios, que poderia ser um facilitador na gestão dos RCCs. Práticas de reutilização, reciclagem ou reuso de materiais de construção inutilizados poderiam resultar em arrecadação financeira para os municípios e ainda permitir a obtenção de certificados de qualidade. Poderia também reduzir as quantidades de material de construção a serem compradas, uma vez que se o município possuísse uma usina de reciclagem o material produzido poderia ser comercializado para o mercado de modo geral ou ainda utilizado em obras realizadas pelo mesmo. Isto acarretaria na geração de renda, 
empregos e redução de custos de compra, na execução de obras.

É necessário conscientizar as empresas e a população sobre o processo de descarte de resíduos, pois executar o mesmo em locais inadequados é prejudicial ao meio ambiente e extremamente oneroso aos cofres públicos, uma vez que o município precisa lidar com esta situação e providenciar a remoção e limpeza. Outro agravante são os danos causados ao meio ambiente que muitas vezes podem ser irreversíveis ou levar anos para se obter uma recuperação.

Outro fator de relevância nesse estudo foi a baixa adesão por parte dos municípios que constituíram o universo da amostra. Inicialmente foi feito contato telefônico informando e solicitando a participação na pesquisa, após houve o envio dos questionários, TCLE e carta de anuência, na sequencia feito outro contato telefônico, confirmando os e-mails e reforçando a solicitação de participação no estudo. Contudo, a devolução dos documentos, foi muito baixa. Recomenda-se um novo estudo no sentido de obter uma adesão de pelo menos cinquenta por cento dos municípios que compõe a RMBH. É importante que Secretários, Gestores e Diretores entendam que a participação nesse tipo de pesquisa possibilita enriquecer o mercado com informações valiosas, que poderiam auxiliar tanto o meio acadêmico, como empresas e construtoras que lidam com os RCCs, nas suas dificuldades o gerenciamento.

\section{REFERÊNCIAS BIBLIOGRÁFICAS}

ALVES, Carlos Eduardo Teobaldo; QUELHAS, Osvaldo L. G. A ecoeficiência e o ecodesign na indústria da construção civil: uma abordagem à prática do desenvolvimento sustentável na gestão de resíduos com uma visão de negócios. Dissertação de mestrado. Rio de Janeiro: Associação Educacional Dom Bosco, 2004. 10p. Disponível em: <http://www.aedb.br/seget/artigos04/106_seget\%20art igo.doc>. Acesso em: abr. 2016.

BARDIN, Lawrence. Análise de conteúdo. Lisboa: Edições 70, 225 p. 1977.

BARRETO, Ismeralda Maria Castelo Branco do Nascimento. Gestão de resíduos na construção civil.
Projeto de pesquisa. Aracaju: SENAI/SE; SENAI/DN; COMPETIR; SEBRAE/SE; SINDUSCON/SE, 2005. 28p.

BRASIL. Conselho Nacional do Meio Ambiente CONAMA. Resoluções do Conama: Resoluções vigentes publicadas entre setembro de 1984 e janeiro de 2012. Ministério do Meio Ambiente. Brasília: MMA, 2012. 1126 p.

BRASIL. Lei Federal no 12.305, de 02 de agosto Institui a Política Nacional de Resíduos Sólidos; altera a Lei no 9.605, de 12 de fevereiro de 1998; e dá outras providências. Diário Oficial da União, Brasília, DF, 03 Ago 2010.

BRASIL. Ministério do Meio Ambiente, Programa Nacional de Educação Ambiental. Sistema Brasileiro sobre Educação Ambiental e Práticas Sustentáveis. Brasília, 2002a. Acessado em: 17/11/2005, disponível em: <http://www.mma.gov.br/port/sdi/ea/index.cfm>.

BRASIL. Resolução n.o 307, de 5 de julho de 2002. Disponível em: <http://www.mma.gov.br/port/ conama/legiabre.cfm?codlegi=307>. Acessado em 13 março de 2016.

BRASIL. Resolução CONAMA no 275, de 25 de abril de 2001. Estabelece o código de cores a ser adotado na identificação de coletores e transportadores, bem como nas campanhas informativas para a coleta seletiva de lixo. Diário Oficial da República Federativa do Brasil, Brasília, 19 jun. 2001

BLUMENSCHEIN, Raquel Naves. Manual técnico: Gestão de Resíduos Sólidos em Canteiros de Obras. Brasília: SEBRAE/DF. 2007. 48 p.

CARNEIRO, A.P.; CASSA, J.C.S.; BRUM, I.A.S. Reciclagem de Entulho para a Produção de Materiais de Construção. Projeto entulho bom. EDUFBA; Caixa Econômica Federal. Salvador. 312 p. 1ạ edição. 2001.

CASTRO, Cristina Xavier de. Gestão de resíduos na construção civil. Monografia. Universidade Federal de Minas Gerais. 2012. 54 p.

CUNHA JÚNIOR, Nelson BoechatCoord. Cartilha de gerenciamento de resíduos sólidos para construção civil. Belo Horizonte: SINDUSCON-MG, 2005. 38 p.

DEGANI, C. M. Sistemas de gestão ambiental em empresas construtoras de edifícios. Dissertação de Mestrado, Escola Politécnica da Universidade de São Paulo. São Paulo, 2003.

DORSTHORST, B.J.H; HENDRIKS, Ch. F. Re-use of construction and demolition waste in the EU. In: CIB Symposium: Construction and Environment - theory into practice., São Paulo, 2000. Proceedings. São Paulo, EPUSP, 2000. 
DRYWALL. Associação Brasileira de Drywall. Nova resolução do Conama define que gesso é totalmente reciclável. 2011 Revista Fator Brasil. [online] Disponível em:

http://www.revistafatorbrasil.com.br/ver_noticia.php?n ot=160684 acesso em abr. 2016.

FAGURY, S.C; GRANDE, F.M. Gestão de resíduos de Construção de DemoliçãoRCD: aspectos gerais da gestão pública de São Carlos/SP. São Carlos, SP. 2007.

FIGUEIREDO, P. J. M. A Sociedade do Lixo: os Resíduos, a Questão Energética e a Crise Ambiental. Piracicaba/SP, Editora UNIMEP, 1994.

GOMES, H. A questão ambiental: Idealismo e Realismo Ecológico. In: Terra Livre, São Paulo, n.3, p.33-54, mar. 1988.

JOHN, Vanderley Moacyr. Reciclagem de resíduos na construção civil: contribuição à metodologia de pesquisa e desenvolvimento. São Paulo, 2010. 102p. Tese livre docência - Escola Politécnica, Universidade de SP.

KARPINSK, L. A.; PANDOLFO, A.; REINEHER, R.; GUIMARÃES, J. C. B.; PANDOLFO, L. M.; KUREK, J. Gestão diferenciada de resíduos da construção civil : uma abordagem ambiental [recurso eletrônico] . Dados eletrônicos. - Porto Alegre : Edipucrs, 163 p. Disponível em: http://www.sinduscondf.org.br/portal/arquivos/ GestaodeResiduosPUCRS.pdf . 2009.

LANGUELL, J. L. Development of a prototype assessment tool to evaluate the potential to successfully implement deconstruction as a regional waste reduction strategy. Ph.D. thesis, Department of Coastal Engineering, University of Florida, 232f. 2001.

LIMA, F. M. da R. de S. A Formação da mineração urbana no Brasil: reciclagem de RCD e a produção de agregados. Tese de Doutorado. Escola Politécnica da Universidade de São Paulo. SP. 2013.

MARTINS, Flávia Gadêlha. Gestão e gerenciamento de resíduos da construção civil em obras de grande porte: estudo de caso. Dissertação de mestrado, Escola de Engenharia de São Carlos, Universidade de São Paulo. São Carlos, 2012.

MINAS GERAIS. Planejamento da Região Metropolitana de Belo Horizonte. 1973. 23 p.

MOURA, Gustavo Muller Gonçalves de. Environmental Issues and Management Structure in Palmas (TO). Goiânia, Faculdade Alves Faria, 2011. 114 p. Dissertação de Mestrado.

OLIVEIRA, Edieliton Gonzaga de; MENDES, Osmar. Gerenciamento de resíduos da construção civil e demolição: Estudo de caso da resolução 307 do Conama. Goiânia, Junho de 2008. Disponível em: < http://pucgoias.edu.br/ucg/prope/cpgss/ArquivosUploa d/36/file/Continua/GERENCIAMENTO.pdf>

PINTO, T. P. (Coord.) Gestão ambiental de resíduos da construção civil: a experiência do Sinduscon-SP, São Paulo: Obra Limpa: I\&T: Sinduscon-SP, 2005.

RESENDE, Luiz Henrique Siqueira. R433a Análise da gestão de resíduos sólidos de construção civil de Belo Horizonte (MG) a partir da percepção dos atores envolvidos [manuscrito] (Dissertação). Universidade de Minas Gerais. 2016. xii, 110 f., enc.: il.

RODRIGUES Gonçalves, Rogério. Tratamento dos resíduos sólidos da construção civil no município de Ibirité - MG. Dissertação Mestrado - Universidade Federal de Ouro Preto. Programa de Pós-Graduação em Sustentabilidade Socioeconômica e Ambiental. 2011. $96 f$.

ROS, Denise Chaves; MAZONI, Patrícia. Porquê e Como elaborar o Projeto de Gerenciamento de Resíduos da Construção Civil. 1ạ Edição. Brasília-DF, 2006.

SCHNEIDER, D.M.; PHILIPPI, A.JR. Public management of construction and demolition waste in the city of São Paulo. Ambiente construído, Porto Alegre, 2004.

SILVA, Roberto Bernardo da; RODRIGUES, Evaldo Cesar Cavalcante; ZAU, Flavia Garcia; TRINDADE, Gabriela Pereira da. Panorama do projeto de gerenciamento de resíduos da construção civil (PGRCC) - estudo de caso na construção do centro administrativo do distrito federal (CADF). In: IV SINVEP Simpósio Internacional de Gestão de Projetos, Inovação e Sustentabilidade. Anais do IV SINGEP - São Paulo - SP - Brasil - 08, 09 e 10 de novembro de 2015.

SILVA, Alex Fabiane Fares da. Gerenciamento de resíduos da construção civil de acordo com a resolução Conama n. 307/02: Estudo de Caso para um conjunto de obras de pequeno porte. Escola de Engenharia da UFMG, Belo Horizonte, 2007. Disponível em http://www.smarh.eng.ufmg.br/defesas/249M.PDF, acessado em mar/2016.

SICEPOT, Manual de sustentabilidade no canteiro de obras. 2014. Disponível em: http://www.sicepotmg.com.br/imagensDin/arquivos/7458.pdf. Acesso mar./2016.

SINDUSCON-MG; SENAI-MG. Gerenciamento de Resíduos Sólidos da Construção Civil. 3‥ Ed. Rev. e Aum. Belo Horizonte: SINDUSCON-MG, 2008. 72p.

SINDUSCON-SP, SINDICATO DA INDÚSTRIA DA CONSTRUÇÃO CIVIL DO ESTADO DE SÃO PAULO. Gestão Ambiental de Resíduos da Construção Civil: a 
Experiência do Sinduscon-SP. São Paulo: SINDUSCONSP,

2005. 48 p. Disponível em:

$<$ http://www.sindusconsp.com.br/teste_secoes.asp?cat eg $=10 \&$ subcateg $=62 \&$ goframe $=$ meioambiente $>$. Acesso em $\mathrm{abr} / 2016$.

SOUZA, U. E. L.; PALIARI, J. C.; AGOPYAN, V.; ANDRADE, A. C. De. Diagnóstico e combate à geração de resíduos na produção de obras de construção de edifícios: uma abordagem progressiva. Ambiente Construído, Porto Alegre, v. 4, n. 4, p. 33-46, out./dez. 2004.

TOZZI, R. F. Estudo da Influência do Gerenciamento na Geração dos Resíduos da Construção Civil RCC - Estudo de Caso de Duas bras em Curitiba/PR. Dissertação Mestrado. Engenharia de Recursos Hídricos e Ambiental - Universidade Federal do Paraná. Curitiba, PR, 2006.
117
p.
Disponível
em:

<http://www.ppgerha.ufpr.br/publicacoes/dissertacoes/ files/123-rafael_fernando_tozzii.pdf $>$. acesso em $\mathrm{abr} / 2016$. 